\title{
A PULSED MODULATOR POWER SUPPLY FOR THE g-2 MUON STORAGE RING INJECTION KICKER*
}

\author{
J. Mi, Y.Y. Lee, W. M. Morse, C.I. Pai, G.C. Pappas, \\ R. Sanders, Y.K. Semertzidis D. Warburton, and R. Zapasek, BNL, Upton, NY, USA \\ K. Jungmann, HU, Heidelberg, Germany, L. Roberts, BU, Boston, MA, USA
}

\section{Abstract}

This paper describes the pulse modulator power supplies used to drive the kicker magnets that inject the muon beam into the $\mathrm{g}-2$ storage ring that has been built at Brookhaven National Laboratory. Three modulators built into coaxial structures consisting of a series circuit of an energy storage capacitor, a damping resistor and a fast thyratron switch are used to energize three magnets that kick the beam into the proper orbit. A $100 \mathrm{kV}$ charging power supply is used to charge the capacitor to $95 \mathrm{kV}$. The damping resistor shapes the magnet current waveform to a 450 nanosecond half-sine to match the injection requirements. This paper discusses the modulator design, construction and operation.

\section{INTRODUCTION}

The goal of high energy physics experiment AGS 821 is to make precision measurements of the muon $\mathrm{g}-2$ value. These measurements require the use of a super-conducting storage ring to store a circulating muon beam. The muon beam intensity in the storage ring is increased by moving the beam into the proper orbit with three kicker magnets after injection.

The kicker magnets are located in the ring, down stream of the inflector. Each of the three kicker magnets is driven by its own pulse modulator power supply. The kicker system deflects the $3.094 \mathrm{GeV} / \mathrm{c}$ momentum beam $10 \mathrm{mrad}^{1}$.

The initial development of the pulse modulator can best be described as long and arduous. The first prototype model used a sparkgap as a switch. While the modulator was able to produce the correct current amplitude and waveform, switch life was limited to at most one million pulses. ${ }^{2}$. The spark gaps of various manufacturers were tested with no improvement in switch life. Many months of $R \& D$ were invested into looking for causes and a solution to electrode deterioration. The gap electrodes were replaced with electrodes of different materials but they failed because of metal migration, pitting and sputtering.
The prototype structure was modified and the sparkgap was replaced by a high voltage thyratron. The modulator was pulsed over three million times without failure.

The modulator is a simple low inductance coaxial structure consisting of a grounded cathode thyratron in series with a damping resistor, an energy storage capacitor and the kicker magnet. The capacitor is charged by a resonant charging power supply. The series discharge resistor provides a load for the circuit. The resistor value was chosen to limit the thyratron current during discharge and to reduce the pulse reverse voltage.

Because of the sensitivities of other systems and instrumentation associated with the storage ring, much thought was given to electromagnetic compatibility (EMC). Consideration was given to the isolation and grounding of all parts of the system. Prevention of electromagnetic interference (EMI), from the high energy circuits was accomplished by using a totally enclosed outer conductor of the modulator and the magnet chamber. Power supply and magnet currents are kept inside to provide a continuous low noise grounding circuit with no external conducted or radiated EMI. All power-wiring conductors are filtered. Instrumentation shields and cabinets also required planning and carefully placed point grounds.

The associated trigger timing system, auxiliary power supplies, and controls are located inside the $\mathrm{g}-2$ ring adjacent to the modulators.

\section{DESIGN AND SIMULATION}

The modulator is required to generate a nominal $450 \mathrm{nsec}$ half-sine $4.3 \mathrm{kA}$ peak current pulse in the kicker magnet. It must operate in a burst mode of six pulses at a $30 \mathrm{~Hz}$ rate with a 2.5 second period. Future requirements include doubling the number of pulses to 12 .

Computer simulations were used to optimize the simple RLC circuit so that the current amplitude and pulse length requirements could be met with realizable

Work performed under the auspices of the U.S. Department of Energy 
components. The kicker magnet consists of a single turn aluminum conductor in vacuum. The inductance of the kicker magnet and its high voltage feedthrough is $1.1 \mu \mathrm{H}$. The inductance of the coaxial line section and thyratron is $0.4 \mu \mathrm{H}$. The simulations confirmed the need for an energy storage capacitor of $10 \mathrm{nF}$, a damping resistor of 11.5 ohms and a charging voltage of $95 \mathrm{kV}$. The simplified circuit model is shown in Figure 1.

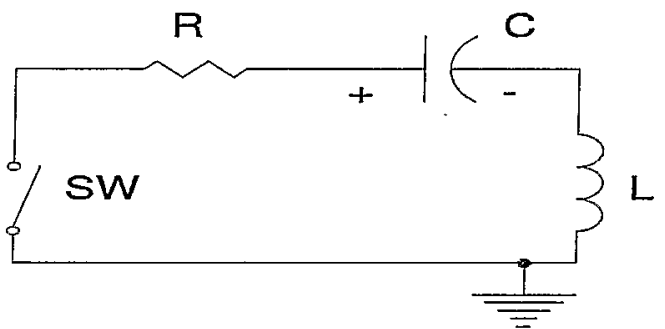

Figure 1. Simplified simulation circuit model.

\section{HIGH VOLTAGE DISCHARGING CIRCUIT ASSEMBLY}

The discharge switch is an EEV type CX1699 four gap hydrogen thyratron shown in Figure 2. It is rated at a 130 $\mathrm{kV}$ maximum peak forward anode voltage. The $10 \mathrm{nF}$ storage capacitor is rated for $100 \mathrm{kV}$. The dumping resistor is a stack assembly consisting of 12 each, 3.75 inch in diameter by 1 inch thick Cesiwid washer resistors sandwiched between copper cooling fin disks for improved internal cooling. The Damping resistor stack is shown in Figure 3.

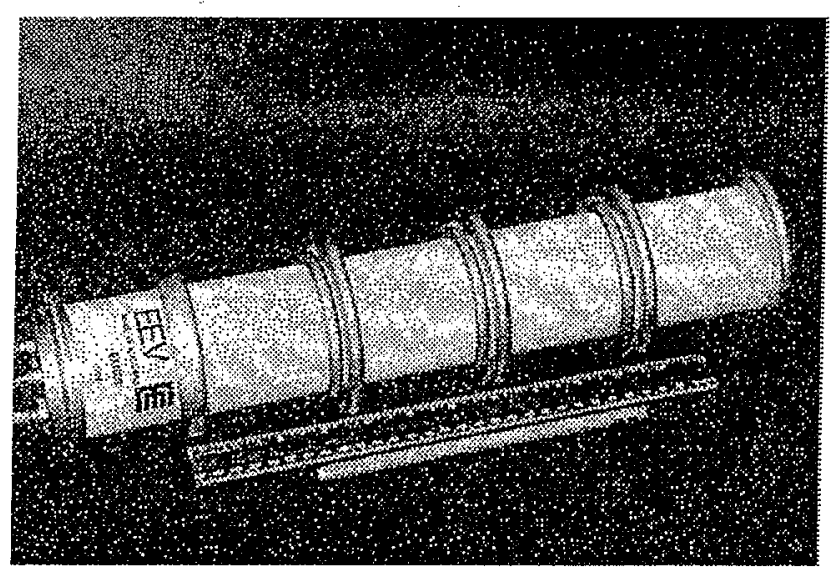

Figure 2. EEV type CX1699 thyratron.

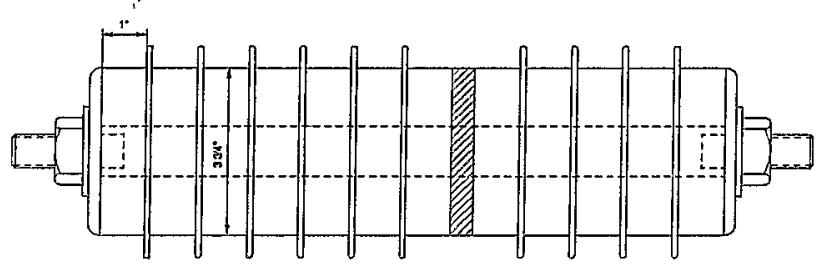

Figure 3. Damping resistor stack assembly.
The capacitor and resistor stack are coaxially mounted in an aluminum pipe filled with a silicon insulating fluid. The thyratron is housed in an accessible rectangular box section filled with the same fluid, at one end of the coaxial line. The other end of the line is provided with a ceramic high voltage feedthrough insulator in a separate section filled with Flourinert FC40 insulating liquid. This insulator provides an interface between the modulator and the magnet vacuum chamber. The outer pipe of the line section is the magnet return conductor. Figure 4 shows the modulator and kicker magnet assembly.

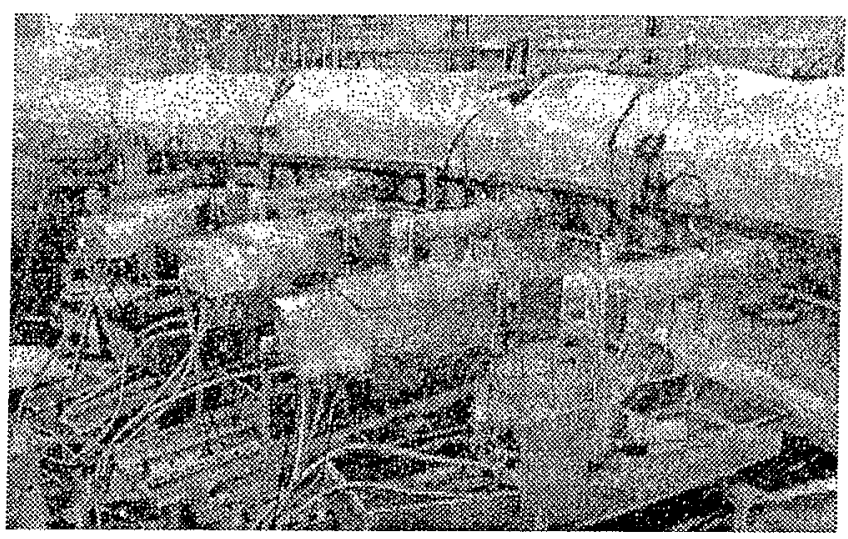

Figure 4. Modulator and kicker magnet assembly.

\section{RESONANT CHARGING SYSTEM}

The system repetition rate of $30 \mathrm{~Hz}$ requires a timing sequence that will allow charging of the energy storage capacitor to the operating voltage in $28 \mathrm{msec}$, and then fire the thyratron $3 \mathrm{msec}$ later. This requirement is accomplished by using a resonant charging power supply. Figure 5 shows the resonant charging power supply. It consists an 85 to 1 step-up transformer with a resonant secondary, that is pulse driven by a lower voltage power supply with energy storage and a switching SCR. The low voltage power supply is inhibited when the SCR and thyratron are conducting.

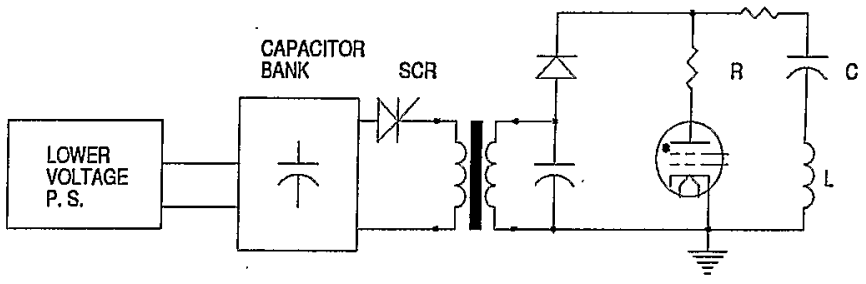

Figure 5. Resonant charging power supply

\section{TRIGGER TIMING SYSTEM}

The operation of the power supplies depends on proper timing and triggering. The major system components are 
located in both the g-2 control room and in the center of the $\mathrm{g}-2$ ring as shown in Figure 6. Fiber optic and transformer links are used where it is necessary to provide noise isolation.

A real time pulse, "AGS Pre-pulse" which is converted to a $27 \mathrm{~ms}$ charge gate for the ALE charging supplies by a digital delay generator, initiates the kicker cycle. An SCR firing trigger is internally generated one millisecond after the end of this gate. The SCR discharges a storage capacitor bank into the resonant charge transformer, charging the main discharge capacitor. At approximately $2 \mathrm{~ms}$ after the charging, an AGS "beam request" trigger which is synchronous to the beam rf phase is received and delayed by approximately 56us. Then, it is fanned out to three individually variable channels (to accommodate individual tube characteristics) and sent to a three channel sequential delay chassis used to minimize timing variations over the 6 burst pulses. These signals are then sent to the MOSFET trigger amplifiers that are transformer coupled to the thyratron grids firing the tubes.

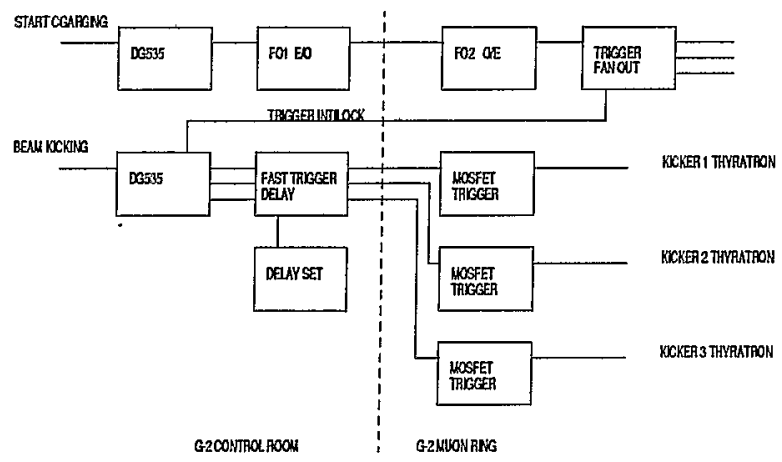

Figure 6. Trigger timing system.

\section{TEST RESULT DATA AND CONCLUSION}

The three modulators and their kicker magnets have been operating successfully without failure for the August 1998 and also the January and February 1999 g-2 physics runs. They have been running at $92 \mathrm{kV}$. Figure 7 shows a typical magnet current pulse at $95 \mathrm{kV}$. The present operating mode is a six pulse burst. In the future the experiment will go to a 12 pulse burst. The modulator has already been tested successfully with 12 pulses. Figure 8 shows a complete system diagram.

\section{ACKNOWLEDGEMENTS}

The authors would like to express their appreciation to A. Soukas, J. Sandberg, W. Zhang, R. Lockey and A. Dunbar for their valuable engineering advice. Also, they would like to thank P. Rosas, J. Makoulis and F. Toldo for their design assistance. Finally, they would like to thank J.
Adessi, P. Benjamin, K. Hartmann, S. Kochis, S. Perlstein and D. Vonlintig for their expeditious help in manufacturing and assembly.

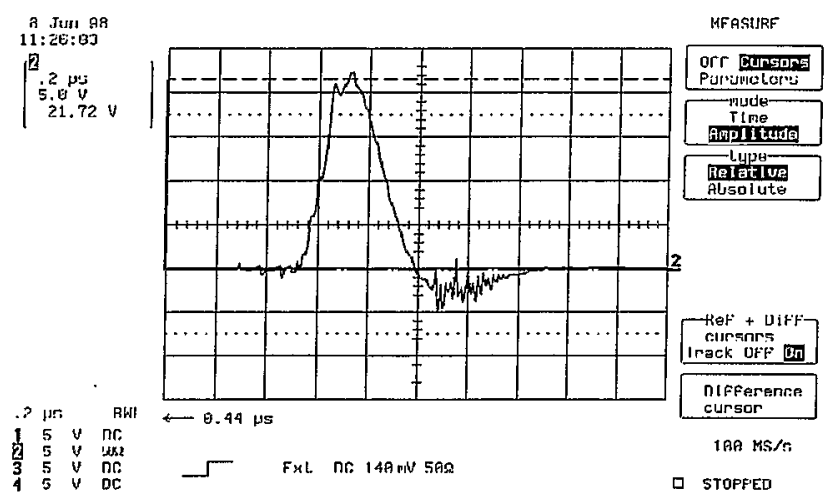

Figure 7. Kicker magnet current waveform (1kA/div, 200nS/div)

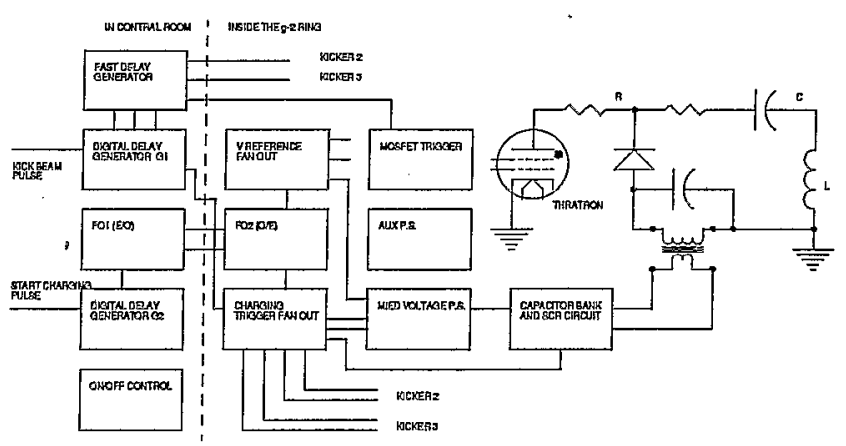

Figure 8. Modulator power supply diagram.

\section{REFERENCE}

1. Muon g-2 Design Report, AGS 821 July 1992, Brookhaven National Laboratory, AUI.

2. "Some High voltage Spark Gap Test Rest Results From The g-2 Kicker Modulator Power Supply" J. Mi, Y.Y. Lee, R. Sanders... 98' High Voltage Workshop October 22-23,1998 